\title{
Complex fine-scale spatial genetic structure in Epidendrum rhopalostele: an epiphytic orchid
}

\author{
Elena Torres $\mathbb{1}^{1} \cdot$ María-Lorena Riofrío ${ }^{2} \cdot$ José M. Iriondo ${ }^{3}$
}

Received: 12 January 2018 / Revised: 6 June 2018 / Accepted: 5 August 2018 / Published online: 5 September 2018

(c) The Genetics Society 2018

\begin{abstract}
Orchid seeds are presumably dispersed by wind due to their very small size and thus can potentially travel long distances. However, the few related studies indicate that seeds fall close to their mother plants. Because seed dispersal and colonization patterns can have relevant consequences for long-term species persistence, we assessed the fine-scale genetic structure of the epiphytic orchid Epidendrum rhopalostele to provide insight into these patterns. All individuals in the studied population were georeferenced and genotyped with AFLP-markers. Genetic structure was evaluated at two levels (forest and tree) using three approaches: principal coordinates analysis, model-based clustering, and spatial autocorrelation analysis. Results showed two genetic groups, composed of individuals from almost every tree with orchids. Spatial autocorrelation analysis at the forest level found no significant genetic structure when all individuals were considered, but a pattern of genetic patches was revealed when the analysis was performed separately for each group. Genetic patches had an estimated diameter of $4 \mathrm{~m}$ and were composed of individuals from more than one tree. A weak genetic structure was detected at the tree level at distances less than $1.5 \mathrm{~m}$. These results suggest that many seeds fall close to the mother plant and become established in the same host tree. Additionally, a sequential colonization process seems to be the predominant mode of expansion, whereby progeny from orchids in one tree colonize neighboring trees. Thus, the existence of two distinct genetic groups and the presence of genetic patches should be considered when seed sampling for ex situ conservation.
\end{abstract}

\section{Introduction}

Fine-scale spatial genetic structure (SGS) is the non-random spatial distribution of genotypes within populations, which results from multiple evolutionary and ecological factors such as microenvironmental selection (Zhou and Chen 2010), plant density (Vekemans and Hardy 2004; Zeng et al. 2012), and limited pollen and seed dispersal (Torres

Electronic supplementary material The online version of this article (https://doi.org/10.1038/s41437-018-0139-1) contains supplementary material, which is available to authorized users.

Elena Torres

elena.torres@upm.es

1 Department of Biotechnology-Plant Biology, Universidad Politécnica de Madrid, Madrid, Spain

2 Department of Biological Sciences, Universidad Técnica Particular de Loja, Loja, Ecuador

3 Area of Biodiversity and Conservation, Universidad Rey Juan Carlos, Móstoles, Spain et al. 2003) among others. Thus, the study of genetic diversity in a spatial context may provide insight into the underlying processes and population dynamics (Ennos 2001; Epperson 2003), which is essential for formulating conservation measures and selecting management options (Diniz-Filho et al. 2008).

Among the factors that shape SGS, seed dispersal is probably the most widely studied and, for many plant species, it has more influence on local patterns of gene flow and genetic structure than pollen dispersal (e.g., Tero et al. (2005) and Jordano (2010)). Two different scenarios are possible, regardless of whether pollen disperses over long or short distances. If seeds fall around the maternal plant, spatial clustering of adults will result in the development of significant fine-scale genetic structure as described by the isolation-by-distance model. Conversely, if seeds are widely dispersed, seed dispersal will effectively randomize the spatial distribution of genetic variation within populations (Hamrick and Nason 1996).

Because orchid seeds are extremely small and light, they can be dispersed by wind (Arditti and Ghani 2000). Only a very slight upwards air movement is required to lift the 
seeds away from the ground, allowing winds to potentially disperse them at long distances [tens or hundreds of kilometers have even been reported, see Arditti and Ghani (2000) and Collins and Brundrett (2015)]. Under this premise, a random spatial distribution of genotypes within populations is expected in the absence of prevailing winds or spatial heterogeneity. However, SGS research on terrestrial orchid populations has found significant genetic structure at distances less than $2 \mathrm{~m}$ (Chung et al. 2005a, 2005b, Jacquemyn et al. 2006, 2009; Helsen et al. 2016), which in most cases has been explained by limited seed dispersal.

For epiphytic orchids, the genetic structuring within populations is more difficult to predict due to the constraints inherent to this type of growth habit. First, differences between vertical and horizontal planes may exist depending on where the plants are growing (i.e., trunks or branches) (Trapnell et al. 2004). Secondly, the height from which seeds are released affects seed dispersal range. Even seeds dispersed from plants at the same height could reach different distances depending on air velocity and forest structure (Cousens et al. 2008). Lastly, another factor is the number and source of founders. If each tree is colonized by one or few founders, SGS would be detected at the tree level, and there would be a low genetic relationship between individuals of different trees. These factors, taken together, highlight a complex structure with at least two hierarchical levels (tree and forest) which may explain the scarce number of SGS studies on epiphytic orchids (Trapnell et al. 2004, 2013) -even though nearly $70 \%$ of all orchids are epiphytes (Zotz 2013) and they represent one of the most threatened plant groups in the world (IUCN 2017).

In the present study, we assessed the fine-scale genetic structure of Epidendrum rhopalostele Hágsater \& Dodson, an epiphytic perennial orchid present in evergreen montane forests, to obtain insight into its seed dispersal pattern and colonization capability. Because sampling an insufficient number of individuals per tree or host trees could provide biased results, all individuals of one population of E. rhopalostele located in a forest south of the Ecuadorian Andes were georeferenced and genotyped by AFLPs (Vos et al. 1995). The relationship among individuals was assessed using three different approaches: principal coordinates analysis (PCoA), clustering based on Bayesian algorithm, and spatial autocorrelation analysis. Position within trees (i.e. trunk or branch) and height above ground of each plant was used to interpret the results in both planes. Specifically, we posed the following questions: (1) Is the population genetically structured?; (2) Are the genotypes randomly distributed within and between trees? If the seeds are dispersed mostly within trees, we expect to find SGS at the forest level; and (3) What are the patterns of seed dispersal and colonization? Finally, we discuss the implications of the results from a conservation point of view.

\section{Material and methods}

\section{Study species}

Epidendrum rhopalostele is a photosynthetic epiphytic perennial orchid native of Ecuador, Peru, and Bolivia that usually occurs in light gaps or along the forest edge in the evergreen montane forest. It is very similar to Epidendrum dialychilum Hágsater \& Dodson, as they both have the lip free from the column, but it differs from the latter in its linear-lanceolate and acuminate lip, the long filiform acuminate petals and the stigmatic cavity only in the apical third of the column (Hágsater et al. 2001). Epidendrum rhopalostele plants are $20-40 \mathrm{~cm}$ long and have an inflorescence with 10-30 bright green flowers. Flowering takes place between January and March and June and August, and capsules ripen between the end of August and the beginning of November (personal observation). Reproduction occurs only by seeds of variable size $(250 \pm 350 \mu \mathrm{m}$ long and $40 \pm$ $55 \mu \mathrm{m}$ wide). Other characteristics about its reproductive biology and seed dispersal mechanism have not been studied and are unknown.

\section{Study site and mapping}

The study site ( 1 ha) was located on the eastern slope of Cordillera Real in the Andes of southern Ecuador on the border of Podocarpus National Park near the Loja-Zamora road in Zamora-Chinchipe province. It is an $~ 35$-year-old regenerated forest classified as an evergreen montane forest (Báez et al. 2013) with more than 70 different genera of vascular plants (Riofrío et al. 2007).

All trees (dead and alive) with a diameter at breast height (DBH) $>1 \mathrm{~cm}$ were georeferenced. Their $x, y$, and $z$ coordinates were obtained using a total station theodolite (Zeiss Elta 6). This device uses an electronic distance measurer (EDM) and an electronic angle scanning to measure distances and angles from the instrument to the points to be surveyed (the base of tree trunks in this case). An integrated microprocessor then calculates the relative coordinates of the target points using trigonometry and triangulation, and the data are recorded in a memory chip. Twelve base points were needed to cover the whole study area.

Each of the mapped trees was examined for the presence of orchids. All E. rhopalostele individuals (adults, juveniles, and seedlings) present at the time of the study were marked and georeferenced, including individuals located as close as $1 \mathrm{~cm}$ from each other. As the high density of 
branches and trees prevented us from visualizing the orchids from the ground, we determined the coordinates of each orchid by laying a plumb line down to the ground and reading the resulting position with the total station. Next, the height at which orchids occurred on their phorophytes was added to the $z$ coordinates measured with the total station.

\section{Sampling for genetic analyses and DNA extraction}

We collected young leaf samples of all E. rhopalostele individuals (adults, juveniles, and seedlings) present in phorophytes for DNA analysis. Leaf material was dried in silica gel and stored at room temperature until DNA extraction.

Total DNA was extracted from $30 \mathrm{mg}$ of dried leaf material using PureLink Plant Total DNA Purification Kit (Invitrogen, Carlsbad, California, USA). After extraction, DNA concentration was estimated using a fluorospectrometer (NanoDrop 3300, Thermo Scientific, Wilmington, Delaware, USA). DNA samples were stored at $-20{ }^{\circ} \mathrm{C}$ until use.

\section{AFLP procedure}

AFLP reactions were performed following the procedure of Vos et al. (1995) with minor modifications. Genomic DNA $(\sim 500 \mathrm{ng})$ was restricted with 0.1 units of MseI (New England BioLabs, Ipswich, Massachusetts, USA) and 0.5 units of EcoRI (Takara Bio Inc., Otsu, Japan) endonucleases, and ligated to MseI and EcoRI adapters with 6 units of T4 DNA-ligase (Takara Bio Inc.). Samples were incubated in a thermocycler for $3 \mathrm{~h}$ at $37^{\circ} \mathrm{C}$ and $1 \mathrm{~h}$ at $17^{\circ} \mathrm{C}$.

Preselective amplification was performed using the primers that complement the MseI and EcoRI adaptors plus one additional nucleotide i.e., MseI $+\mathrm{C}\left(5^{\prime}\right.$ GAT GAG TCC TGA GTA AC $\left.3^{\prime}\right)$ and EcoRI + A (5'-GAC TGC GTA CCA ATT CA-3'). PCR reactions were conducted in $12.5 \mu \mathrm{l}$ reaction volume containing $2.5 \mu \mathrm{l}$ of 10 -fold diluted restriction-ligation product, $1 \times$ buffer (GeneAmp 10× PCR Buffer II, Applied Biosystems, California, USA), $1.5 \mathrm{mM}$ $\mathrm{MgCl}_{2}, 0.2 \mathrm{mM}$ dNTPs, $0.2 \mu \mathrm{M}$ of each primer, and 0.5 units of Taq polymerase (AmpliTaq DNA Polymerase, Applied Biosystems). The thermocycler program used for amplifications was as follows: $72^{\circ} \mathrm{C}$ for $2 \mathrm{~min}$, then 30 cycles at $94{ }^{\circ} \mathrm{C}$ for $30 \mathrm{~s}, 56^{\circ} \mathrm{C}$ for $30 \mathrm{~s}$, and $72{ }^{\circ} \mathrm{C}$ for $2 \mathrm{~min}$, with a final extension at $72{ }^{\circ} \mathrm{C}$ for $10 \mathrm{~min}$. The quality of undiluted preselective and restricted/ligation products was tested on $1 \%(\mathrm{w} / \mathrm{v})$ agarose gels.

Selective amplifications were conducted in a reaction volume of $12.5 \mu$ l containing $2.5 \mu \mathrm{l}$ of 10 -fold diluted preselective product, $1 \times$ buffer (GeneAmp 10× PCR Buffer II, Applied Biosystems), $1.5 \mathrm{mM} \mathrm{MgCl}_{2}, 0.8 \mathrm{mM}$ dNTPs,
$0.08 \mu \mathrm{M}$ of EcoRI fluorescent primer (Applied Biosystems), $0.2 \mu \mathrm{M}$ of MseI primer (Bonsai Advanced Technologies, Alcobendas, Madrid, Spain), and 0.5 units of Taq polymerase (AmpliTaq Gold DNA Polymerase, Applied Biosystems). PCR conditions were: $95^{\circ} \mathrm{C}$ for $2 \mathrm{~min}$, then 13 cycles at $94^{\circ} \mathrm{C}$ for $30 \mathrm{~s}, 65^{\circ} \mathrm{C}$ for 1 min (with a decrease gradient of $0.7^{\circ} \mathrm{C}$ every cycle), and $72{ }^{\circ} \mathrm{C}$ for $2 \mathrm{~min}$; and 24 cycles at $94{ }^{\circ} \mathrm{C}$ for $30 \mathrm{~s}, 56{ }^{\circ} \mathrm{C}$ for $1 \mathrm{~min}$, and $72{ }^{\circ} \mathrm{C}$ for $2 \mathrm{~min}$, with a final extension at $72^{\circ} \mathrm{C}$ for $10 \mathrm{~min}$.

Four primer combinations producing clear bands were used for selective amplification: MseI-CTA/EcoRI-AGA (6FAM), MseI-CAC/EcoRI-AGA(6FAM), MseI-CAA/ EcoRI-AAC(VIC), and MseI-CAT/EcoRI-AGG(VIC). The selection was based on a preliminary screening of 32 primer combinations in five individuals (three individuals from different trees and two from the same tree).

AFLP fragments were separated on an ABI 3730 sequencer (Applied Biosystems). A gene scan 500 Liz-labeled sizes standard (Applied Biosystems) was injected with each AFLP sample to allow sizing of the DNA fragments.

To assess reproducibility of the protocol, two independent DNA extractions were carried out for eight samples. The error rate for each locus was calculated as the ratio of the total number of mismatches (band presence vs. band absence) to the total number of replicated individuals (Bonin et al. 2007).

\section{Data analysis}

AFLP profiles were imported into GeneMarker v. 4.1 (Softgenetics) and scored manually. All bands between 80 and $500 \mathrm{bp}$ were scored as present (1) or absent (0) excluding those that could not be decisively assigned. Monomorphic and polymorphic fragments were included in the analysis.

\section{Detection of genetic structure}

As a preliminary step, a principal coordinates analysis (PCoA) was carried out to provide a visual representation of the genetic distance relationships among the sampled individuals of E. rhopalostele. Following Bonin et al. (2007), a simple matching coefficient was used to calculate the distance matrix.

Next, population structure was inferred by applying model-based clustering methods. Unlike distance-based clustering, these methods use a model to identify genetic groups from the full set of genotype data and to probabilistically assign individuals (or a fraction of their genomes) to each group, representing the best fit for the variation patterns found. We used the approach implemented in Structure v. 2.3.4, which involves Bayesian inference and 
parameter estimation through Markov Chain Monte Carlo (MCMC) in the modeling process (Pritchard et al. 2000; Falush et al. 2007). For analysis with Structure, we used the admixture model (which assumes individuals may have mixed ancestry) with correlated allele frequencies (Falush et al. 2003), and set the number of groups ( $K)$ from 1 to 10 . For each value of $K, 10$ independent runs were carried out with a burn-in period of 10,000 followed by 300,000 MCMC iterations. The optimal number of groups was determined estimating the log-likelihood of the data for each $K[\ln (\mathrm{P}(\mathrm{X} \mid \mathrm{K})]$ as suggested by Pritchard et al. (2000), and the $\Delta \mathrm{K}$ statistic proposed by Evanno et al. (2005), which is based on the rate of change in the log-likelihood of data between successive $K$ values. Afterwards, the FullSearch algorithm of the software CLUMPP v. 1.1.2 (Jakobsson and Rosenberg 2007) was used to find the optimal alignment of 10 independent replicate cluster analyses and to compute the membership coefficient matrix (Qmatrix).

Once the optimal number of groups was determined, an AMOVA was used to test whether the genetic differentiation (measured by $\phi_{\mathrm{ST}}$ ) was significant. The analysis was performed using GenAlEx v. 6.5 (Peakall and Smouse 2012), with $n=9999$ permutations. The values provided in Q-matrix were used to assign individuals to each group taking $q>0.5$ as threshold value.

\section{Detection of SGS}

SGS was assessed at the forest level (i.e., to evaluate the relation between individuals of the same and different trees in the studied forest) and at the tree level (i.e., at a distance range that focuses on individuals within a tree). In both cases, we used the spatial autocorrelation method proposed by Smouse and Peakall (1999) and implemented in GenAlEx, which simultaneously assesses the signal generated by multiple loci. Briefly, this approach calculates an autocorrelation coefficient $(r)$ between genetic and geographic distances for all pairs of individuals within user specified distance classes. Under isolation-by-distance, geographically close individuals are expected to be more genetically similar to each other than to other individuals occurring at greater distances. Therefore, $r>0$ values are expected for shortdistance lags and $r<0$ for long-distance lags.

Genetic distances between all pairs of orchids were calculated using the method of Huff et al. (1993). Similarly, Euclidean distances of all pairs of orchids were computed from their $x, y$, and $z$ coordinates. At the forest level, distance classes were defined at $1 \mathrm{~m}$ intervals, each including at least 30 pairs of points as recommended by Waser and Mitchell (1990). We also followed a classical rule of thumb and only considered pairs of points separated by less than half the maximum distance observed (Le Corre et al. 1998), which in our case was $15 \mathrm{~m}$ for the forest level. At the tree level, distance classes were defined at $0.25 \mathrm{~m}$ intervals following the above-mentioned sampling size considerations. In this case, the distance range covered in the analysis was $2 \mathrm{~m}$, which included over $95 \%$ of the distances between individuals of the same tree and was lower than half the maximum distance observed.

Each value of $r$ was tested for significant deviations from the expected value under the null hypothesis of no SGS by a permutation in which all AFLP phenotypes were randomly shuffled among the spatial positions occupied and $r$-values recalculated each time (up to a maximum of 9999 times) (see Smouse and Peakall (1999) and Smouse et al. (2008) for details). As we are interested in detecting positive autocorrelation in the short-distance classes, one-tailed probability values were calculated. The significance of $r$ was also tested by generating bootstrap 95\% confidence intervals around the mean value of $r$. Bootstrap values were obtained by sampling, with replacement, pairs of comparisons within a given distance class (Peakall et al. 2003). Bootstrap resampling was performed 9999 times and the significance of $r$ inferred when the $95 \%$ confidence interval did not contain the zero value. Significance of the entire correlogram was tested using the heterogeneity test proposed by Smouse et al. (2008), considering a significance level of 0.01 (Banks and Peakall 2012).

The spatial autocorrelation analysis was repeated for each group identified by Structure because the individuals of the two genetic pools were located in the same trees. When this occurs, spatially close individuals are not necessarily more genetically similar than individuals which are farther apart. So, the presence of genetic neighborhoods could not be detected in the overall correlogram. The autocorrelation patterns generated for each group were compared (at both the distance class and whole correlogram levels) using the nonparametric heterogeneity test proposed by Smouse et al. (2008).

Finally, we built contour maps to help interprate correlograms at the forest level (Escudero et al. 2003). For this, a principal component analysis (PCA) was performed, and the first extracted axis was used to generate a genetic similarity map. The kriging algorithm implemented in Surfer v. 8 was used as a gridding method.

\section{Results}

We found E. rhopalostele on only 25 of the 714 trees found in the studied forest fragment (Supplementary Figure 1). The number of orchids per phorophyte ranged from 1 to 32 , with a total of 239 individuals located mainly on tree trunks. 




Fig. 1 Bi-dimensional plot of the principal coordinate analysis (PCoA) obtained from four AFLPs combinations in 216 Epidendrum rhopalostele individuals

AFLP analysis was successful in 216 of the 239 individuals, and provided a total of 621 bands between 80 and $500 \mathrm{bp}$, with a $2 \%$ average error rate. $100 \%$ of the studied loci were polymorphic, and most of them (64\%) had a frequency lower than 0.23 .

\section{Population genetic structure}

The scatter-plot of the first and the second axis of the PCoA showed two distinct groups (Fig. 1). Visualization of results considering the phorophytes on which orchids are located showed no relationship between the two genetic groups and orchid spatial distribution. Nor was any association found when the type of individual (adult or juvenile) was considered. The first two principal coordinates accounted for $22 \%$ of total variance (18\% for PCoA1 and 4\% for PCoA2).

The Bayesian clustering analysis conducted by Structure also identified two genetic groups (hereafter, called group 1 and group 2). As shown in Fig. 2, the first value of $\ln \mathrm{P}(\mathrm{X})$ at which the curve reaches the plateau $(-57513.6)$ and the highest $\Delta K$ value (714.6) were found for $K=2$, indicating that the genetic structure produced by dividing all genotypes into two groups is the most likely. For $K=2$, most individuals (152 of 216) had admixture coefficients over 0.8 (Supplementary Figure 2).

The two groups identified by Structure showed a low but statistically significant level of genetic differentiation according to AMOVA results $\left(\phi_{\mathrm{ST}}=0.076, P<0.001\right)$, and had similar values of genetic diversity estimated as percentage of polymorphic loci, Shannon's information index and expected heterozygosity (Supplementary Table 1).

It is also remarkable that 21 of 25 phorophytes had individuals of both groups (Table 1 and Supplementary Figure 2).

\section{Detection of SGS}

When all individuals were analyzed together, no genetic spatial autocorrelation was observed at the forest level $(\omega=$ 55.8, $P=0.014$; Fig. 3a) or at the tree level $(\omega=30.6, P=$ 0.023; Fig. 3b). However, when the data set was divided according to the genetic groups assigned by Structure, significant correlograms were obtained for lag-distances of $1 \mathrm{~m}(\omega 1=149.6, P<0.001 ; \omega 2=170.2, P<0.001)$ and $0.25 \mathrm{~m}(\omega 1=102.3, P<0.001 ; \omega 2=65.9, P<0.001)$ evidencing the presence of genetic structure within groups.

At the forest level, the correlogram for group 1 showed significant positive autocorrelation in the first three distance classes $(1 \mathrm{~m}, r=0.063, P<0.001 ; 2 \mathrm{~m}, r=0.056, P<$ $0.001 ; 3 \mathrm{~m}, r=0.033, P=0.005)$ and a first $\mathrm{x}$-intercept of $r$ at $4.1 \mathrm{~m}$ (Fig. 4c). Therefore, individuals below this threshold share higher genetic similarity than more spatially distant individuals. In group 2, we also found significant positive $r$-values for individuals in the first, third, and fourth distance classes ( $1 \mathrm{~m}, r=0.025, P<0.001 ; 3 \mathrm{~m}, r=0.016$, $P=0.006 ; 4 \mathrm{~m}, r=0.029, P=0.005)$ and an $\mathrm{x}$-intercept at $4.6 \mathrm{~m}$ (Fig. 4c). Another remarkable result is the alternation from positive to negative autocorrelation values in both correlograms, which is characteristic of a pattern of patches. Although correlograms had a similar shape, they were statistically different according to the heterogeneity test $(\omega=$ 51.3, $P<0.001)$. In particular, the distance classes $1(\omega=$ $11.1, P=0.001), 2(\omega=24.2, P<0.001)$, and $14(\omega=$ 29.3, $P<0.001)$ had significantly higher absolute autocorrelation values in group 1 than in group 2 .

At the tree level, the correlogram for group 1 showed significant positive autocorrelation in almost all distance classes $(0.25 \mathrm{~m}, r=0.098 ; 0.50 \mathrm{~m}, r=0.068 ; 0.75 \mathrm{~m}, r=$ $0.064 ; 1.25 \mathrm{~m}, r=0.079 ; 2 \mathrm{~m}, r=0.074$ ) (Fig. $4 \mathrm{~d}$ ). In group 2, the correlogram also detected significant but weaker positive autocorrelation at very short distances (0.25 m, $r=0.024 ; 0.5 \mathrm{~m}, r=0.019 ; 0.75, r=0.030 ; 1 \mathrm{~m}$, $r=0.026)$ and an X-intercept of $r$ at $1.4 \mathrm{~m}$ (Fig. 4d).

Contour maps of the consensus genetic variable showed a pattern of irregular closed loops in both groups (Fig. 4b).

\section{Discussion}

This is one of the few studies so far reporting on the analysis of the SGS of an epiphytic orchid at the tree level (i.e., individuals within a tree) and forest level (i.e., individuals of different trees in the same forest). In this population with a total of 239 E. rhopalostele individuals located in only 25 of 714 possible phorophytes, we detected a complex genetic structure in which several ecological and evolutionary processes seem to be acting. Some aspects that need to be taken into account to adequately interpret the results are the 
Fig. 2 Optimal number of genetic clusters in the studied Epidendrum rhopalostele population according to the admixture model with correlated alleles implemented in Structure. a The log-likelihood of the data $[\ln \mathrm{P}(\mathrm{X})]$ averaged over 10 consecutive Structure runs for $K$ $=1$ to 10 , with error bars representing \pm standard deviation. b Evanno's $\Delta K$ statistic plotted against $K$ a)



b)

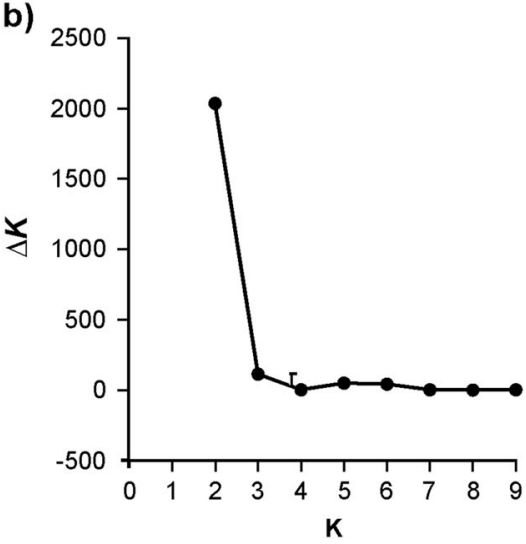

Table 1 Number of Epidendrum rhopalostele individuals per phorophyte belonging to group 1 or group 2 according to the admixture model with correlated alleles implemented in Structure

\begin{tabular}{|c|c|c|c|}
\hline ID phorophyte & Group 1 & Group 2 & Total \\
\hline Tree 1 & 11 & 18 & 29 \\
\hline Tree 2 & 1 & 2 & 3 \\
\hline Tree 3 & 1 & 2 & 3 \\
\hline Tree 4 & 6 & 11 & 17 \\
\hline Tree 5 & 9 & 11 & 20 \\
\hline Tree 6 & 2 & 5 & 7 \\
\hline Tree 7 & 3 & 5 & 8 \\
\hline Tree 8 & 2 & 2 & 4 \\
\hline Tree 9 & 1 & 1 & 2 \\
\hline Tree 10 & 1 & 0 & 1 \\
\hline Tree 11 & 10 & 9 & 19 \\
\hline Tree 12 & 1 & 5 & 6 \\
\hline Tree 13 & 4 & 6 & 10 \\
\hline Tree 14 & 3 & 6 & 9 \\
\hline Tree 15 & 2 & 2 & 4 \\
\hline Tree 16 & 1 & 3 & 4 \\
\hline Tree 17 & 12 & 20 & 32 \\
\hline Tree 18 & 1 & 3 & 4 \\
\hline Tree 19 & 0 & 3 & 3 \\
\hline Tree 20 & 6 & 4 & 10 \\
\hline Tree 21 & 2 & 6 & 8 \\
\hline Tree 22 & 3 & 4 & 7 \\
\hline Tree 23 & 0 & 1 & 1 \\
\hline Tree 24 & 0 & 2 & 2 \\
\hline Tree 25 & 2 & 1 & 3 \\
\hline Total & 84 & 132 & 216 \\
\hline
\end{tabular}

Assignment to groups is based on the admixture coefficient using a threshold value of 0.5

age and structure of the forest, and the patchy and dynamic character of the epiphyte habitat, as they influence genetic structure across time and space.

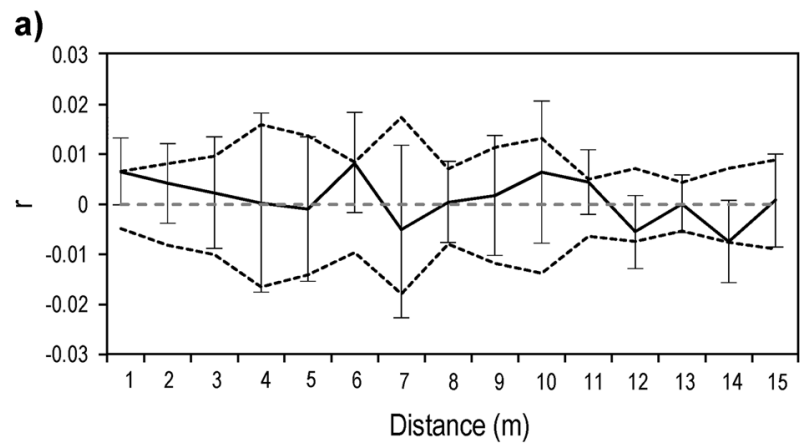

b)

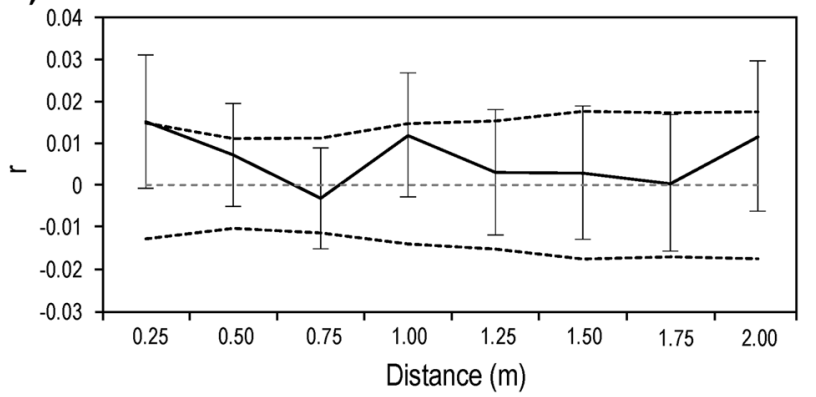

Fig. 3 Spatial genetic structure of 216 Epidendrum rhopalostele individuals located on 21 trees at two levels (a forest and b tree). Autocorrelograms are based on geographic distance classes of equal size: $1 \mathrm{~m}$ for forest level, and $0.25 \mathrm{~m}$ for tree level. Dashed lines represent the $95 \%$ confidence interval about the null hypothesis of $r=$ 0 as determined by a permutation test; error bars represent $95 \%$ confidence intervals about $r$ derived from bootstrapping

\section{Population genetic structure}

Two different genetic groups were found according to PCoA and Structure results. Although genetic structure can arise through spatial factors, for example, as consequence of environmental heterogeneity, examination of the orchid distribution on phorophytes clearly shows that this is not the cause because there were orchids of both groups in 21 of the 25 phorophytes (see Table 1). For this same reason, a scenario based on the "propagule-pool" colonization model 


\section{Group 1}

a)



b)

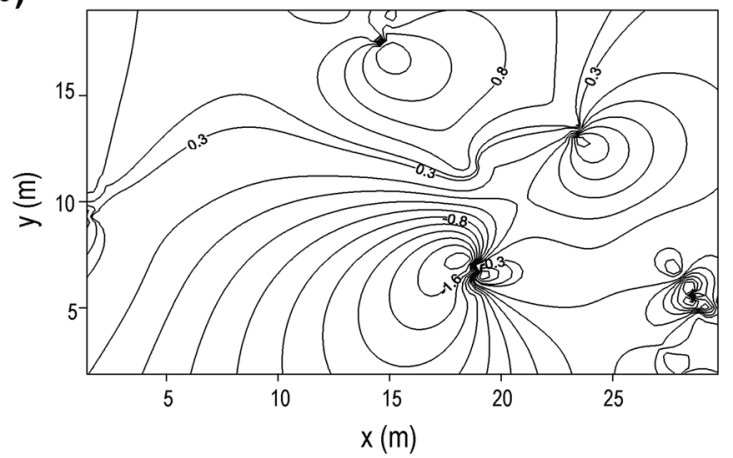

c)

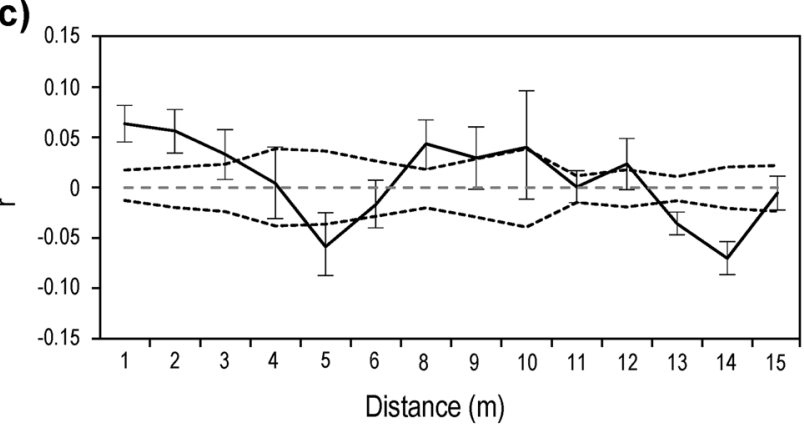

d)



(Slatkin and Wade 1978) could not be considered either. Furthermore, it is very unlikely that founders from two

\section{Group 2}
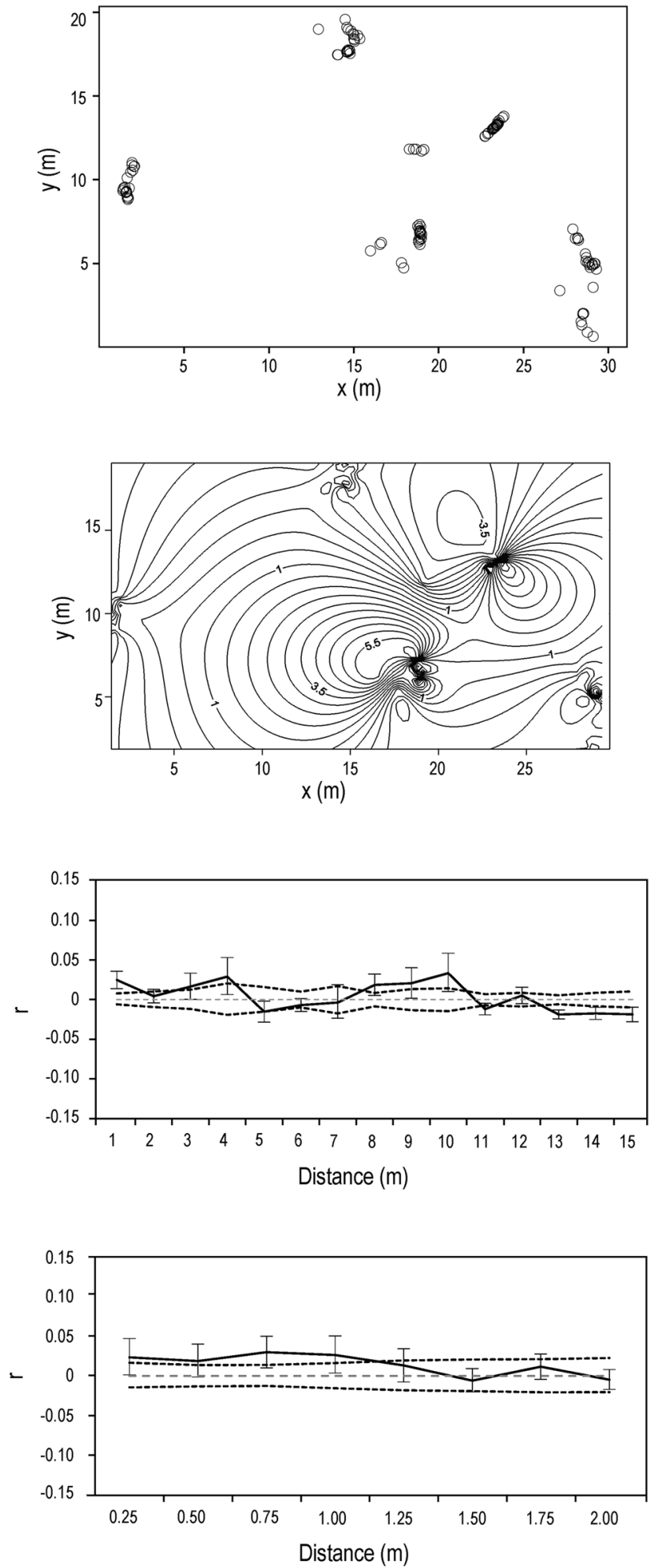

different sources would have established in the same 21 trees considering the high tree-density in the study area and 
Fig. 4 Results of the spatial genetic structure analysis at tree and forest levels for each group identified by Structure according to the admixture model with correlated alleles. a Spatial distribution of the Epidendrum rhopalostele individuals. b Contour maps depicting the isolines and the associated gray scale of the synthetic genetic variable obtained with the first extracted axis of a principal components analysis (PCA). c Autocorrelograms at the forest level showing the genetic correlation coefficient $(r)$ as a function of geographical distance. Distance classes range from 0 to 15 with $1 \mathrm{~m}$ intervals. d Autocorrelograms at the tree level showing the genetic correlation coefficient $(r)$ as a function of geographical distance. Distance classes range from 0 to 2 with $0.25 \mathrm{~m}$ intervals. Dashed lines represent the 95\% confidence interval about the null hypothesis of $r=0$ as determined by a permutation test; error bars represent $95 \%$ confidence intervals about $r$ derived from bootstrapping. Graphics on the left side correspond to the 84 individuals from group 1, and graphics on the right side to the 132 individuals from group 2

the low phorophyte specificity of E. rhopalostele (Riofrío 2015). Neither can these two genetic groups be explained by differences between age-classes because adults, juveniles, and seedlings were found in both groups, suggesting that there is no differential selection between life-cycle stages.

Other possible explanations for the observed genetic structure are the presence of cryptic ecotypes or interspecific hybrids in the population. In some orchids with deceptive pollination, genetic differences have been related to ecotypes that exhibit different floral scents and attract different pollinator species (Menz et al. 2015; Phillips et al. 2015). Further studies to identify the pollinators of E. rhopalostele and the composition of floral scent are needed to test this hypothesis. Regarding the possible gene flow between $E$. rhopalostele and other closely related Epidendrum species, there is some evidence supporting this scenario: (1) a total of 51 individuals of E. madsenii Hágsater \& Dodson were found in the study area, and most of them were located in the same trees as E. rhopalostele (Lorena Riofrío, Universidad de Loja, personal observation); (2) hybridization events have recently been reported in populations where $E$. rhopalostele and E. madsenii coexist (Marques et al. 2014); (3) a high degree of compatibility between these two species has been found, mainly when E. rhopalostele acts as an ovule donor (Marques et al. 2014); and (4) F1 hybrids between E. rhopalostele and E. madsenii are fertile, and in most cases they are morphologically indistinguishable from their maternal parents (Marques et al. 2014). Further studies using other molecular markers are also needed to test this second hypothesis.

\section{Are the genotypes randomly distributed within and among trees?}

Different genetic patterns can be detected according to the sign and direction of change in the spatial autocorrelation coefficient. In our study, when all individuals in the forest fragment were considered, a profile of random fluctuation of the autocorrelation coefficient around zero was obtained, suggesting no SGS. However, the significant correlograms obtained for distance classes of $1 \mathrm{~m}$ when the two genetic groups were considered separately, shows that genotypes in this population are not randomly distributed. The presence of individuals of both groups in the same trees would explain the lack of SGS when all individuals are analyzed together.

When positive SGS is found, the first $\mathrm{x}$-intercept has often been considered an estimate of genetic patch size (Escudero et al. 2003; Peakall et al. 2003) and, therefore, of the scale at which the pattern occurs. However, some authors recommend interpreting this value with caution because spatial autocorrelation can be affected by the sampling design and the distance class sizes chosen (Vekemans and Hardy 2004). In our case, these limitations are not relevant because all individuals present in the study area were included in the analysis, and the 1-m lag size allowed us to detect genetic structure. Hence, we can assume the presence of a patchy genetic structure with a width of $4.1 \mathrm{~m}$ for group 1 and $4.6 \mathrm{~m}$ for group 2 . Because these values are greater than the maximum distance between individuals of the same tree in $99 \%$ of the cases, we infer that the genetic patches include individuals of more than one phorophyte and, therefore, genotypes are not randomly distributed among trees. The shape of spatial-contour maps also supports this interpretation, as in most cases, isolines include orchids of neighboring trees.

At the tree level, inferences about the processes that are occurring need to be made with caution. The correlograms revealed a significant but weak SGS in both groups. This result is indicative of a family structure with genotypes randomly distributed within trees. However, the overlapping of different genetic patterns derived from differences in the demographic structure within each phorophyte or in the colonization pattern would be blurring the overall genetic pattern, leaving a weak signal of SGS.

\section{What are the patterns of seed dispersal and colonization?}

The presence of significant positive $r$-values at distances less than $2 \mathrm{~m}$ indicates genetic relatedness (i.e., family structure) between individuals of the same tree, supporting the idea that most E. rhopalostele seeds fall (and become established) in the immediate vicinity of their mother plants. This pattern of short-distance seed dispersal agrees with the results for other epiphytic orchids such as Laelia rubescens Lindley (Trapnell et al. 2004) and Brassavola nodosa (L.) Lindley (Trapnell et al. 2013) in which significant SGS was detected at the tree level. 
On the other hand, the detection of genetic patches with a diameter of four meters suggests a sequential colonization process whereby progeny from orchids in one tree colonize neighboring trees. Additionally, the patchy genetic pattern inferred from the correlograms at the forest level supports the idea that E. rhopalostele seeds may occasionally travel longer distances. The positive $r$-values at distance classes of 8 and 9 meters could be attributed to the colonization of new trees by sporadic seed dispersal events to greater distances. In this sense, it is interesting to note that the colonization of distant trees must have occurred recently in the population and that the movement of pollinators among tree groups is limited; otherwise overlap of successive generations and gene flow would have increased genetic similarity between plants of different trees blurring this scenario. In any case, colonization events must be rare considering that E. rhoplalostele was present in only $3.5 \%$ of trees and the presence of suitable phorophytes was not a limiting factor (Riofrío 2015).

\section{Conservation implications}

Many epiphytic orchids are endangered by the high level of deforestation in recent decades (Laurance 2013). Under this scenario, knowing the fine-scale SGS is important because it provides useful information in conservation decisionmaking. In this E. rhopalostele population, the observation that seed dispersal occurs mostly within phorophytes increases the risk of local extinction because the fall of a phorophyte can imply a sharp reduction in population size and consequently reduce genetic diversity. In forests where colonization by the orchid is in its initial stages, the oftenobserved problem of fallen orchids due to the instability of the substrate (flaking bark or breaking branches) could be addressed by relocating the orchids in nearby trees in order to reduce the risk of local extinction and accelerate the process of expansion. Another consideration is the possible presence of hybrids in the population. If introgression is naturally occurring, E. madsenii should be taken into account to maintain evolutionary processes (Fitzpatrick et al. 2015). Finally, the seed collecting strategy for ex situ conservation should include both individuals of the same tree (to represent the two genetic groups) and individuals of several trees separated by at least $4 \mathrm{~m}$ (to capture intragroup genetic diversity).

\section{Conclusion and future prospects}

Analysis of genetic data using different approaches has allowed us to identify several genetic clusters that would otherwise have gone unnoticed. Similarly, spatial information has helped us to detect two genetic groups in this population. The interpretation of results considering both planes has provided insight into colonization processes at the tree level and forest level, which could be useful for the conservation of this species as well as other epiphytic orchids. Nevertheless, an extension of this study to other $E$. rhopalostele populations would be recommended to know how seed dispersal patterns vary among forests with different structures. Studies on population dynamics, seedling establishment, or reproductive biology should also be initiated to support in situ conservation actions.

\section{Data archiving}

The data sets used for this study, including the location of each orchid within the study forest and AFLP loci, are available in e-cienciaDatos (https://edatos.consorcioma drono.es/) under doi:10.21950/SL9WLS.

Acknowledgements The authors thank C. Naranjo for his field assistance; Dr. P. Vargas for the technical support in the generation of AFLP data; L. De Hond for her linguistic assistance; and two anonymous reviewers for helpful comments and suggestions made on an earlier version of this manuscript. This research was partially supported by the SENESCYT (Grant no. CEREPS-2006 2007072) and Universidad Politécnica de Madrid.

\section{Compliance with ethical standards}

Conflict of interest The authors declare that they have no conflict of interest.

\section{References}

Arditti J, Ghani AKA (2000) Numerical and physical properties of orchid seeds and their biological implications. New Phytol $145: 367-421$

Báez S, Santiana J, Guevara J (2013). Bosque siempreverde montano del Sur de la Cordillera Oriental de los Andes. In: Ministerio del Ambiente del Ecuador 2012 (ed) Sistema de clasificación de los ecosistemas del Ecuador continental. Ministerio del Ambiente del Ecuador, Quito, Ecuador, pp 123-125

Banks SC, Peakall R (2012) Genetic spatial autocorrelation can readily detect sex-biased dispersal. Mol Ecol 21:2092-2105

Bonin A, Ehrich D, Manel S (2007) Statistical analysis of amplified fragment length polymorphism data: a toolbox for molecular ecologists and evolutionists. Mol Ecol 16:3737-3758

Chung MY, Nason JD, Chung MG (2005a) Patterns of hybridization and population genetic structure in the terrestrial orchids Liparis kumokiri and Liparis makinoana (Orchidaceae) in sympatric populations. Mol Ecol 14:4389-4402

Chung MY, Nason JD, Chung MG (2005b) Spatial genetic structure in populations of the terrestrial orchid Orchis cyclochila (Orchidaceae). Plant Syst Evol 254:209-219

Collins M, Brundrett M (2015) Recovery of terrestrial orchids in natural ecosystems after severe disturbance. In: Tibbett $M$ (ed) Mining in ecologically sensitive landscapes. CSIRO Publishing, Clayton South, Australia, p 142-158

Cousens R, Dytham C, Law R (2008) Dispersal in Plants. A Population Perspective. Oxford University Press, Oxford, UK

Diniz-Filho JAF, de Campos Telles MP, Bonatto SL, Eizirik E, de Freitas TRO, de Marco P et al. (2008) Mapping the evolutionary 
twilight zone: molecular markers, populations and geography. J Biogeogr 35:753-763

Ennos RA (2001) Inferences about spatial processes in plant populations from the analysis of molecular markers. In: Silvertown J, Antonovics $\mathbf{J}$ (eds) Integrating ecology and evolution in a spatial context. Blackwell Science, Oxford, UK, p 45-72

Epperson BK (2003) Space-Time population genetics. In: Epperson BK (ed) Geographical genetics. Princeton University Press, Princeton, New Yersey, p 1-10

Escudero A, Iriondo J, Torres M (2003) Spatial analysis of genetic diversity as a tool for plant conservation. Biol Conserv 113:351-365

Evanno G, Regnaut S, Goudet J (2005) Detecting the number of clusters of individuals using the software STRUCTURE: a simulation study. Mol Ecol 14:2611-2620

Falush D, Stephens M, Pritchard JK (2003) Inference of population structure using multilocus genotype data: linked loci and correlated allele frequencies. Genetics 164:1567-1587

Falush D, Stephens M, Pritchard JK (2007) Inference of population structure using multilocus genotype data: dominant markers and null alleles. Mol Ecol Notes 7:574-578

Fitzpatrick BM, Ryan ME, Johnson JR, Corush J, Carter ET (2015) Hybridization and the species problem in conservation. Curr Zool 61:206-216

Hágsater E, Dodson CH, Sánchez Saldaña L, Cervantes L, Dressler RL, Silverstone-Sopkin PA (2001) Icones Orchidacearum. The genus Epidendrum. Herbario AMO, Mexico City, Mexico

Hamrick JL, Nason JD (1996) Consequences of dispersal in plants. In: Rhodes O, Chesser R, Smith M (eds) Population dynamics in ecological space and time. University of Chicago Press, Chicago, Illinois, p 203-246

Helsen K, Meekers T, Vranckx G, Roldán-Ruiz I, Vandepitte K, Honnay O (2016) A direct assessment of realized seed and pollen flow within and between two isolated populations of the fooddeceptive orchid Orchis mascula. Plant Biol 18:139-146

Huff DR, Peakall R, Smouse PE (1993) RAPD variation within and among populations of outcrossing buffalograss [Buchloë dactyloides (Nutt.) Engelm]. Theor Appl Genet 86:927-934

IUCN (2017) The IUCN Red List of Threatened Species. Version 2017-3

Jacquemyn H, Brys R, Vandepitte K, Honnay O, Roldán-Ruiz I (2006) Fine-scale genetic structure of life history stages in the fooddeceptive orchid Orchis purpurea. Mol Ecol 15:2801-2808

Jacquemyn H, Wiegand T, Vandepitte K, Brys R, Roldán-Ruiz I, Honnay O (2009) Multigenerational analysis of spatial structure in the terrestrial, food deceptive orchid Orchis mascula. J Ecol 97:206-216

Jakobsson M, Rosenberg NA (2007) CLUMPP: a cluster matching and permutation program for dealing with label switching and multimodality in analysis of population structure. Bioinformatics 23:1801-1806

Jordano P (2010) Pollen, seeds and genes: the movement ecology of plants. Heredity 105:329-330

Laurance WF (2013) Emerging threats to tropical forests. In: Lowman M, Devy S, Ganesh T (eds) Treetops at risk. Springer, New York, NY, pp 71-79

Le Corre V, Roussel G, Zanetto A, Kremer A (1998) Geographical structure of gene diversity in Quercus petraea (Matt.) Liebl. III. Patterns of variation identified by geostatistical analyses. Heredity 80:464-473

Marques I, Draper D, Riofrío L, Naranjo C (2014) Multiple hybridization events, polyploidy and low postmating isolation entangle the evolution of neotropical species of Epidendrum (Orchidaceae). BMC Evol Biol 14:20

Menz MHM, Phillips RD, Anthony JM, Bohman B, Dixon KW, Peakall R (2015) Ecological and genetic evidence for cryptic ecotypes in a rare sexually deceptive orchid, Drakaea elastica. Bot J Linn Soc 177:124-140

Peakall R, Ruibal M, Lindenmayer DB (2003) Spatial autocorrelation analysis offers new insights into gene flowin the australian bush rat, Rattus fuscipes. Evol 57:1182-1195

Peakall R, Smouse PE (2012) GenAlEx 6.5: genetic analysis in Excel. Population genetic software for teaching and research-an update. Bioinformatics 28:2537-2539

Phillips RD, Bohman B, Anthony JM, Krauss SL, Dixon KW, Peakall $\mathrm{R}$ (2015) Mismatch in the distribution of floral ecotypes and pollinators: insights into the evolution of sexually deceptive orchids. J Evol Biol 28:601-612

Pritchard JK, Stephens M, Donnelly P (2000) Inference of population structure using multilocus genotype data. Genetics 155:945-959

Riofrío ML (2015). Estudio de los factores que condicionan a escala local la presencia de Epidendrum rhopalostele: Implicaciones para su conservación. PhD Thesis, Universidad Politécnica de Madrid.

Riofrío L, Naranjo C, Iriondo JM, Torres E (2007) Spatial structure of Pleurothallis, Masdevallia, Lepanthes and Epidendrum epiphytic orchids in a fragment of montane cloud forest in South Ecuador. Lankesteriana 7:102-106

Slatkin M, Wade MJ (1978) Group selection on a quantitative character. Proc Natl Acad Sci USA 75:3531-3534

Smouse PE, Peakall R (1999) Spatial autocorrelation analysis of individual multiallele and multilocus genetic structure. Heredity 82:561-573

Smouse PE, Peakall R, Gonzales E (2008) A heterogeneity test for fine-scale genetic structure. Mol Ecol 17:3389-3400

Tero N, Aspi J, Siikamäki P, Jäkäläniemi A (2005) Local genetic population structure in an endangered plant species, Silene tatarica (Caryophyllaceae). Heredity 94:478-487

Torres E, Iriondo JM, Escudero A, Pérez C (2003) Analysis of withinpopulation spatial genetic structure in Antirrhinum microphyllum (Scrophulariaceae). Am J Bot 90:1688-1695

Trapnell DW, Hamrick JL, Ishibashi CD, Kartzinel TR (2013) Genetic inference of epiphytic orchid colonization; it may only take one. Mol Ecol 22:3680-3692

Trapnell DW, Hamrick JL, Nason JD (2004) Tree-dimensional finescale genetic structure of the neotropical epiphytic orchid Laelia rubescens. Mol Ecol 13:1111-1118

Vekemans X, Hardy OJ (2004) New insights from fine-scale spatial genetic structure analyses in plant populations. Mol Ecol 13:921-935

Vos P, Hogers R, Bleeker M, Reijans M, Van de Lee T, Hornes M et al. (1995) AFLP: a new technique for DNA fingerprinting. Nucleic Acids Res 23:4407-4414

Waser NM, Mitchell RJ (1990) Nectar standing crops in Delphinium nelsonii flowers: Spatial autocorrelation among plants? Ecology 71:116-123

Zeng X, Michalski SG, Fischer M, Durka W (2012) Species diversity and population density affect genetic structure and gene dispersal in a subtropical understory shrub. J Plant Ecol 5:270-278

Zhou H-P, Chen J (2010) Spatial genetic structure in an understorey dioecious fig species: the roles of seed rain, seed and pollenmediated gene flow, and local selection. J Ecol 98:1168-1177

Zotz G (2013) The systematic distribution of vascular epiphytes-a critical update. Bot J Linn Soc 171:453-481 